(2014). A Longitudinal Study on Learner Career Advancement in MOOCs. Journal of Learning Analytics, 1 (3), $203-206$.

\title{
A Longitudinal Study on Learner Career Advancement in MOOCs
}

\author{
Yuan Wang, Luc Paquette, and Ryan Baker \\ Columbia University Teachers College, USA \\ elle.wang@columbia.edu
}

\begin{abstract}
In this paper, we present progress towards a longitudinal study of the post-course career advancement of MOOC learners. We present initial results and analysis plans for how to link this to in-course behaviour, towards better understanding the goals of all MOOC learners.
\end{abstract}

KEYWORDS: Learning Analytics, MOOCs, massive open online courses, career advancement

\section{INTRODUCTION}

MOOCs, massive open online courses, have garnered worldwide attention as a new platform for learning over the past three years. A growing community of researchers from various disciplines have studied engagement patterns in MOOC (e.g., Kizilcec, Piech, \& Schneider, 2013; Clow, 2013), and found out $\mathrm{MOOC}$ learners exhibited highly varied ways of interacting with and using the courses they enroll in. Unlike in traditional online learning platforms, many $\mathrm{MOOC}$ learners do not consider completing a course their primary goal (Fini, 2009; Belanger \& Thornton, 2013). Although the dropout rate is very high, it is generally agreed that completion rate in the context of MOOCs cannot be easily equated with previous generations of learning platforms (cf. DeWaard et al., 2011).

As such, challenges have been raised on how to define learner success in the context of MOOCs (e.g., Breslow et al. 2013). This question is pertinent in that traditional metrics assessing the success of online learning may not be relevant to the needs and goals of MOOC learners. Existing research has focused on two dimensions in addressing this question: achievement and persistence. First, some studies of learner success have examined metrics mirroring a traditional classroom, such as grades of quizzes and exams (cf. Belanger \& Thornton, 2013; MOOC @ Edinburgh, 2013). Second, studies linking success with persistence focused on learner usage and participation with course components such as videos (e.g., Guo, Kim, \& Rubin, 2014) and discussion forums (e.g., Yang, Sinha, David, \& Rose, 2013).

Since data on MOOC learner information is highly fragmented and diffuse (McAulay, Stewart, \& Siemens, 2010), it may be useful to incorporate data beyond the immediate course platform and the pre-designated time frame for a specific course in the efforts of better understanding learner behaviour. However, little has been investigated in terms of how a MOOC has impacted a student beyond 1) the duration of the course prescribed by the instructor or the design of the course platform and 2) the context of the course platform itself. Therefore, we propose an inclusive plan to study student success, going beyond interactions with the course itself, but also by taking into account data collected beyond the constraints of the course and course platform. Specifically, we will investigate the effects of course participation on longitudinal data reflecting participant career advancement after taking the MOOC. 
(2014). A Longitudinal Study on Learner Career Advancement in MOOCs. Journal of Learning Analytics, 1 (3), 203-206.

\section{METHOD}

The proposed research is being carried out within the context of a MOOC, "Big Data in Education," delivered via Coursera in Fall 2013. As introduced in the previous section, we plan to integrate course data with longitudinal data in order to better understand and assess learner success in the context of MOOCs. To this end, we have obtained multiple data sources. First, achievement during the course is represented by course grade data on student performance on eight weekly assignments. Second, persistence is represented by log data capturing learner behaviour interacting with course components together with text data extracted from the discussion forums. These data were obtained in a raw form, and much feature engineering will be required. In addition, variables extracted from an early course motivational survey, measuring student academic efficacy and goal orientation, and an exit survey, measuring student intent on future direction after the course, have been collected. Third, for community participation, we have started to look into career advancement and learner participation in communities of practice after taking the MOOC. This can be measured in several ways, including looking at whether students choose to join relevant societies, such as the International Educational Data Mining Society, attended conferences, such as the Learning Analytics and Knowledge Conference and the International Conference on Educational Data Mining, and published in relevant fields. In addition, social media participation will be studied. We will then develop predictive models that infer longitudinal participation from interactions within the course.

\section{RESULTS AND DISCUSSION}

The exit survey indicated that 430 out of 536

intended skills of this $\mathrm{MOOC}$ in their career. Going forward from this to community participation, we have found that 35 students who registered for the MOOC joined the International Educational Data Mining Society after the course started. Preliminary analyses indicated that these 35 students disproportionately completed the course; $20 \%$ of students who joined the society completed the course, whereas only $1.3 \%$ of the remaining students $\operatorname{did}(\chi 2(1)=97.438, p<0.001)$. Although 35 is a small number in comparison to the total enrollment, it only reflects one small aspect of community participation. Further learner participation data will also be collected.

The present study sets the goal of investigating MOOC impact and learner success longitudinally by using course data to predict career-related learner decisions and trajectories after the course finishes. This project therefore has the goal of investigating $\mathrm{MOOC}$ learner success beyond traditional indicators of successful course completion. This study is aimed toward understanding what aspects in the use of MOOCs are predictive of eventual public participation in the community of practice. As such, if this project is successful, it may contribute to our understanding of what it means for a MOOC to succeed, and how the effectiveness of a MOOC can be assessed more comprehensively. 
(2014). A Longitudinal Study on Learner Career Advancement in MOOCs. Journal of Learning Analytics, 1 (3), 203-206.

\section{REFERENCES}

Charleer, S., Klerkx, J., Odriozola, S. L., \& Duval, E. (2013). Improving awareness and reflection through collaborative, interactive visualizations of badges. Proceedings of the 3rd Workshop on Awareness and Reflection in Technology-Enhanced Learning. Paphos: CEUR Workshop Proceedings, online http://ceur-ws.org/Vol-1103/paper5.pdf

Charleer, S., Santos, J. L., Klerkx, J., \& Duval, E. (2014a). LARAe: Learning analytics reflection and awareness environment. Proceedings of the 4th Workshop on Awareness and Reflection in Technology-Enhanced Learning. Graz: CEUR Workshop Proceedings, online http://ceurws.org/Vol-1238/paper9.pdf

Charleer, S., Santos, J. L., Klerkx, J., \& Duval E. (2014b). Improving teacher awareness through activity, badge and content visualizations. In Y. Cao, T. Väljataga, J. K. T. Tang, H. Leung and M. Laanpere (Eds.), New Horizons in Web Based Learning: Proceedings of the 1st International Workshop on Open Badges in Education (LNCS) (pp. 143-152). Tallinn: Springer.

Gould, J. D., \& Lewis, C. (1985). Designing for usability: Key principles and what designers think. Communications of the ACM, 28(3), 300-311.

Isenberg, P., Elmqvist, N., Scholtz, J., Cernea, D., Ma, K.-L., \& Hagen, H. (2011). Collaborative visualization: Definition, challenges, and research agenda. Information Visualization, 10(4), 310326.

Kelly, A. (2004). Design research in education: Yes, but is it methodological? The Journal of the Learning Sciences, 13(1), 115-128.

Martinez Maldonado, R., Kay, J., Yacef, K., \& Schwendimann, B. (2012). An interactive teacher's dashboard for monitoring groups in a multi-tabletop learning environment. In S. A. Cerri, W. J. Clancey, G. Papadourakis and K. Panourgia (Eds.), Intelligent Tutoring Systems (LNCS) (Vol. 7315, pp. 482-492). Crete: Springer.

Siemens, G., \& Long, P. (2011). Penetrating the fog: Analytics in learning and education. Educause Review, 46(5), 30-32.

Silius, K., Tervakari, A.-M., \& Kailanto, M. (2013). Visualizations of user data in a social media enhanced web-based environment in higher education. Global Engineering Education Conference (pp. 893-899). Berlin: IEEE.

Shneiderman, B. (1996). The eyes have it: A task by data type taxonomy for information visualizations. IEEE Symposium on Visual Languages (pp. 336-343). IEEE.

Verbert, K., Duval, E., Klerkx, J., \& Govaerts, S. (2013). Learning analytics dashboard applications. American Behavioral Scientist, 57(10), 1500-1509.

Verbert, K., Govaerts, S., Duval, E., Santos, J., Van Assche, F., Parra, G., et al. (2014). Learning dashboards: An overview and future research opportunities. Personal and Ubiquitous Computing, 18(6), 1499-1514. 
(2014). A Longitudinal Study on Learner Career Advancement in MOOCs. Journal of Learning Analytics, 1 (3), 203-206.

Wang, F., \& Hannafin, M. J. (2005). Design-based research and technology-enhanced learning environments. Educational Technology Research and Development, 53(4), 5-23.

Wolff, A., Zdrahal, Z., Nikolov, A., \& Pantucek, M. (2013) Improving retention: Predicting at-risk students by analysing clicking behaviour in a virtual learning environment. Proceedings of the 3rd International Conference on Learning Analytics and Knowledge (pp. 145-149). Leuven: ACM. 